Politische Philosophie

in der Weimarer Republik 
NORBERT J. SCHÜRGERS

\section{Politische Philosophie in der \\ Weimarer Republik}

Staatsverständnis

zwischen Führerdemokratie

und bürokratischem Sozialismus

J.B. Metzlersche Verlagsbuchhandlung Stuttgart 
CIP-Titelaufnahme der Deutschen Bibliothek

Schürgers, Norbert:

Politische Philosophie in der Weimarer Republik :

Staatsverständnis zwischen Führerdemokratie und

bürokratischem Sozialismus / Norbert Schürgers. - Stuttgart :

Metzler, 1989

Zugl.: Tübingen, Univ., Diss.

ISBN 978-3-476-00664-6

ISBN 978-3-476-03281-2 (eBook)

DOI 10.1007/978-3-476-03281-2

Dieses Werk einschließlich aller seiner Teile ist urheberrechtlich geschützt. Jede Verwertung außerhalb der engen Grenzen des Urheberrechtsgesetzes ist ohne Zustimmung des Verlages unzulässig und strafbar. Das gilt insbesondere für Vervielfältigungen, Übersetzungen, Mikroverfilmungen und die Einspeicherung und Verarbeitung in elektronischen Systemen.

(C) 1989 Springer-Verlag GmbH Deutschland Ursprünglich erschienen bei J.B. Metzlersche Verlagsbuchhandlung und Carl Ernst Poeschel Verlag GmbH in Stuttgart 1989 
„Vieles leuchtet erst, nachdem es verlorenging." ERNST BLOCH

Für Meike 


\section{INHALTSVERZEICHNIS}

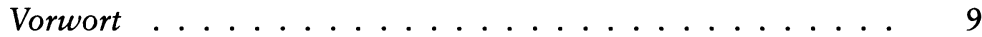

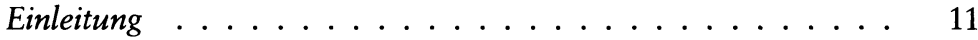

A. Zentrale Aspekte politischer Philosophie IN DER WeIMARER REPUBLIK

I. Basistheoreme sozialistischer Philosophie . . . . . . . . . 26

1. Philosophie in weltverändernder Absicht . . . . . . . 26

2. Anthropologische Grundlegung des Sozialismus . . . . . . . 30

3. Revolution statt Reform . . . . . . . . . . . . . . 35

4. Das Proletariat als Subjekt der Geschichte . . . . . . . . . 39

5. Notwendigkeit einer Avantgarde im revolutionären Prozeß . . . . . . . . . . . . . . 42

6. Republik und Demokratie als Vorstufen des Sozialismus . . . 48

7. Die Verkennung der faschistischen Gefahr oder Der Feind steht links . . . . . . . . . . . 56

II. Basistheoreme liberaler Philosophie . . . . . . . . . . . 61

1. Philosophie in welt- und existenzerhellender Absicht . . . . 62

2. Macht als anthropologisch-gesellschaftliche Konstante . . . 66

3. Bedrohung des Individuums durch die Masse . . . . . . . . 70

4. Demokratie als Mittel zum Schutze des Individuums . . . . 73

5. Parlament und Parteien im Dienste des "Staatsmannes" . . . . 80

6. Vereinbarkeit von Diktatur und Rechtsstaat . . . . . . . . 83

B. Politische Philosophie der Weimarer Republik IN EINZELANALYSEN

I. Sozialistische Positionen . . . . . . . . . . . . . . . 90

1. Wurzeln sozialistischer Demokratietheorie (Marx/Engels) . . 90

2. Bürokratischer Staatssozialismus (W.I. Lenin) . . . . . . . . 99

3. Demokratie als Bedingung des Sozialismus (R. Luxemburg) . 106 
4. Identität von Demokratie und Sozialismus (E. Bloch) . . . . . 111

5. Mitleid und Empörung (M. Horkheimer) . . . . . . . . . . 123

6. Die "totale Revolution" (H. Marcuse) . . . . . . . . . . . . 138

7. »Ursprungskräfte« im Dienste des Sozialismus (P. Tillich) . . . 155

8. Rechtsphilosophie und Klassenkampf (G. Radbruch) . . . . . 173

II. Bürgerlich-liberale Positionen . . . . . . . . . . . . . . 183

1. Charismatische Führerdemokratie (M. Weber) _. . . . . 183

2. Macht und Schicksal (Th. Litt) . . . . . . . . . . . . . . 192

3. Politik als Organon der Anthropologie (H. Plessner) . . . . . 212

4. Der Staat als Ort existenzieller Selbstfindung (K. Jaspers) . . . 220

5. Christliche Demokratie im deutschen Obrigkeitsstaat (M. Scheler) . . . . . . . . . . . . . . . . . 236

C. Die Konservativ-völkische StaATs- Und DEMOKRATIEAUFFASSUNG

1. Demokratie - Die menschliche Verfallsform (F. Nietzsche) _. 258

2. Heraufkunft des Cäsarismus (O. Spengler) _. . . . . . . 259

3. Furcht vor der Herrschaft der Stiefelputzer (O. Spann) . . . . 263

4. Vision des Dritten Reiches (A. Moeller van den Bruck) . . . 266

5. Emanzipation der Volksgemeinschaft (H. Freyer) . . . . . . 268

6. Sichüberliefern an das Da des Augenblicks (M. Heidegger) . . 270

7. Krieg als Wesensmerkmal des Politischen (C. Schmitt) . . . . 274

Schlußbemerkung . . . . . . . . . . . . . . 277

Anmerkungen . . . . . . . . . . . . . . . . . . 279

Literaturverzeichnis . . . . . . . . . . . . . . . . 370 


\section{VORWORT}

Politische Philosophie der Weimarer Republik wird, wenn sie in der einschlägigen Forschungsliteratur überhaupt Beachtung findet, fast ausnahmslos mit antidemokratischem Denken gleichgesetzt. Dies ist durchaus verständlich, bedenkt man, daß sich zwischen 1919 und 1933 im Bereich der Politik- und Demokratietheorie vor allem konservativ-nationalistische und deutsch-völkische Ideologen hervortaten. Von Philosophen aus dem mittleren und linken politischen Spektrum der zwanziger Jahre sucht man vergeblich nach umfassenden Arbeiten zu diesem für die junge deutschen Republik so wichtigen Gebiet.

Nur einige wenige (sozialdemokratische) Juristen und Staatsrechtler bemühten sich redlich, den Weimarer Staat und seine demokratische Verfassung gegen die wütenden und diffamierenden Angriffe von rechts zu verteidigen, indem sie zumindest den theoretisch-prinzipiellen Kampf aufnahmen.

Wenn dennoch in dieser Arbeit der Frage nachgegangen wird, ob und in welchem Ausmaß die Weimarer Philosophie, die nicht dem konservativen bzw. völkischen Lager angehörte, das Feld der Politik und die Bedeutung der Republik in ihm thematisiert hat, so deshalb, weil die nähere Beschäftigung mit sozialistischen und bürgerlich-liberalen Philosophen dieser Zeit ergab, daß sich einige von ihnen des (politischen) Themas doch stärker angenommen hatten, als sich aufgrund des vorherrschenden Desinteresses zunächst vermuten ließe.

Die gängige These, daß diese erste deutsche Republik zwar viele Feinde, aber keine Freunde hatte, wird auch die vorliegende Untersuchung nicht entkräften können - aber sie wird vielleicht aufzeigen können, daß sich die Feindschaft nicht immer gegen die Demokatie und die Republik als solche, sondern nur gegen ihre spezifische Weimarer Form richtete.

Ich möchte an dieser Stelle nicht versäumen, mich bei den Tübinger Philosophieprofessoren Helmut Fahrenbach, Rolf Denker und Eberhard Braun zu bedanken, die die vorliegende, leicht überarbeitete und um das Abschlußkapitel ergänzte Untersuchung als Doktorarbeit betreuten; ferner bei meinen Freunden, die mir mit Rat, Wissen und Verständnis zur Seite standen, ganz besonders aber bei Meike Werner, Ursula Konnertz, Luiz E. Bicca, Helmut Gold, meinem Bruder Georg sowie meinen Eltern für ihre großzügige finanzielle Unterstützung. 